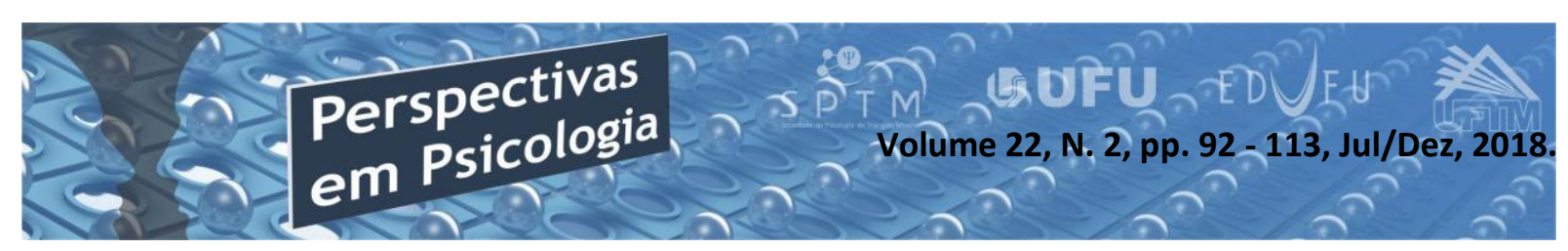

\title{
HABITAÇÃO SOCIAL E PARTICIPAÇÃO POPULAR - UM ESTUDO SOBRE AS DIRETRIZES DO PROGRAMA MINHA CASA MINHA VIDA
}

\author{
Douglas Cardoso da Silva \\ (Universidade de São Paulo - USP - São Paulo - SP)
}

\begin{abstract}
Resumo
Este estudo procura analisar as possibilidades de participação popular no Programa Minha Casa Minha Vida. Tendo por base a análise dos documentos oficiais que definem as diretrizes de implementação do programa, buscamos destacar o papel designado ao futuro morador e os meios que possibilitariam sua participação. Consideramos que eles são extremamente reduzidos, o que evidencia o papel passivo destinado ao público alvo, uma vez que a menção à sua possível participação se encontra limitada a apenas um dos itens do programa: o trabalho social, cujo poder de alcance também é restrito. Assim, apesar dos seus méritos, o Programa Minha Casa Minha Vida permanece dominado por uma dinâmica burocrática e autoritária que impede qualquer protagonismo dos moradores: real obstáculo à superação da desigualdade política.
\end{abstract}

Palavras-chave: Programa Minha Casa Minha Vida; participação popular; trabalho ocial; burocracia; modelo de gestão pública.

\begin{abstract}
Social Housing and Popular Participation: A Research of the Guidelines of the Program "Minha Casa Minha Vida"

This article aims to analyze the processes of popular participation in the Program "Minha Casa Minha Vida". Based on the analysis of official documents that define the guidelines issued by the Federal Government for implementing the Program, we seek to emphasize the assignment of the future inhabitant and which are the means that would enable their participation in the process that will set their houses. We conclude that these are strictly limited, which reinforces the passive role for the inhabitant, considering that in the rules of the Program, any reference of their possible participation is restricted to one of its items: social work, whose power of reach is also very limited. In spite of its merits, the program remains dominated by bureaucratic and authoritarian dynamics that preclude the leading role of the inhabitants: real obstacle to overcoming the political inequality.
\end{abstract}

Keywords: Program "Minha Casa Minha Vida"; popular participation; social work; bureaucracy; public management model. 


\section{Introdução}

O processo de urbanização no Brasil ocorreu, sobretudo, ao longo do Século XX, acentuando-se na segunda metade deste período. Na década de 1970 , pela primeira vez, a população urbana supera a rural, atingindo 56\%. Na década de 1980, esse número chega a $68 \%$, alcançando 81 milhões de moradores nas cidades brasileiras (Bonduki, 2014). Contudo, o cenário urbano não se transformou em espaço de reconfiguração de algumas características do período colonial e imperial, como a concentração de terra, renda e poder. Pelo contrário, com a urbanização torna-se ainda mais patente o processo de segregação: a partir do início da década de 1980, as periferias crescem mais do que os núcleos ou municípios centrais nas metrópoles e surgem, pela primeira vez na história do país, extensas áreas de concentração de pobreza, as quais se encontravam relativamente esparsas nas zonas rurais (Maricato, 2003).

Ao longo desse intenso processo de urbanização, a população pobre trabalhadora instala-se nas áreas recusadas pelo mercado imobiliário privado e em espaços públicos localizados em regiões desvalorizadas: beira de córregos, encostas dos morros, terrenos sujeitos a enchentes ou outros tipos de riscos, regiões poluídas, áreas de proteção ambiental. Nesses locais, nascem bairros construídos pelos próprios moradores, sem qualquer contribuição de arquitetos e engenheiros, bairros em que é regra a inobservância da legislação urbanística ou de quaisquer outras leis. A força de trabalho aqui empregada não se encaixa no mercado residencial privado formal, é uma força de trabalho barata, segregada e excluída da cidade legal (Maricato, 2013).

Apesar do exponencial e desordenado crescimento urbano, somente nos anos 2000 é criado um novo quadro jurídico e institucional ligado às cidades, o qual se relaciona com a questão política fundiária, de habitação, saneamento, mobilidade e resíduos sólidos. Nesse sentido, constituem marcos importantes e progressistas a inclusão do direito à moradia na Constituição (2001), a criação do Ministério das Cidades (2003), a nova formulação de uma Política Nacional de Habitação (2004) e do Plano Nacional de Habitação (2008). A implantação de novos programas de urbanização e moradia é reflexo desse novo quadro: em 2007, o governo federal cria o Programa de Aceleração do Crescimento (PAC), com finalidade de alavancar o emprego na indústria da construção; em 2009, são 
lançados o PAC II e o Programa Minha Casa Minha Vida (PMCMV). O novo momento despertou o interesse de investidores no mercado imobiliário brasileiro, resultando em um forte aporte de capital estrangeiro no setor (Bonduki, 2014).

Para atendimento da demanda de novos empreendimentos, ocorreu uma ávida busca por terrenos aptos para habitação, o que gerou um processo especulativo que chegou a ser considerado, entre 2007 e 2008, um boom imobiliário (Bonduki, 2014). De um lado, houve considerável aumento do produto interno bruto (PIB) do país e redução da taxa de desemprego, sobretudo na construção civil (de 12,8\% em 2003 para 2,7\% em 2012). De outro, o impacto no mercado imobiliário é descomedido: em São Paulo houve aumento de $153 \%$ no preço dos imóveis entre 2009 e 2012; no Rio de Janeiro, o aumento chegou a $184 \%$. Tal cenário acirra ainda mais a disputa por terras entre o capital imobiliário e a classe trabalhadora, ampliando as fronteiras da expansão urbana e expulsando os pobres para a periferia da periferia (Maricato, 2013).

A localização dos empreendimentos do Programa Minha Casa Minha Vida para atendimento de famílias de baixa renda não escapa a esta dinâmica, como demonstram os estudos de Rolnik (2014) nas regiões metropolitanas de São Paulo e Campinas, em que se pode constatar o predomínio de novos conjuntos habitacionais em áreas periféricas. "Se o programa passou a atingir uma camada da população historicamente não atendida pelas iniciativas federais na área habitacional, não chegou a interferir em seu 'lugar' histórico nas cidades, reproduzindo o padrão periférico." (Rolnik, 2014, p. 7)

Os conjuntos habitacionais do $P M C M V$, portanto, não devem ser pensados como ilhas isoladas da cidade, mas como espaços que nascem imantados por tensões históricas inerentes a um intenso e desordenado processo de urbanização e às consequentes dificuldades de acesso à moradia digna e à cidade pelas classes mais vulneráveis. Considerando esse cenário, buscamos analisar os documentos oficiais que estabelecem as diretrizes do PMCMV, publicados pelo Ministério das Cidades (MCidades), na tentativa de identificar as possibilidades de participação popular no programa federal, tentando compreender a dinâmica que domina a implementação do $P M C M V$. Com esse intuito foram analisados vinte documentos, incluindo Portarias publicadas pelo MCidades, além de leis e decretos sancionados pela Presidência da República entre os anos de 2009 e 2014 (período que compreende as duas primeiras fases do programa, no qual as metas para contratação de novas unidades foram significativamente 
maiores). Destacaram-se neste estudo os documentos que de fato representaram alguma mudança na mecânica de funcionamento do $P M C M V$, relacionada ao papel dos seus atores e/ou da participação popular (ou os define).

Reconhecer a questão da participação popular como elemento fundamental de análise do programa é fruto do desenvolvimento de um trabalho de observação participante de aproximadamente cinco anos, realizado em diversos empreendimentos localizados na cidade de São Paulo e região metropolitana. Portanto, a necessidade de aprofundar o estudo das diretrizes do PMCMV nasceu de questões concretas: tentativa de superar obstáculos e identificar se uma dinâmica percebida como inibidora de processos participativos populares é ou não decorrente de uma eventual distorção das diretrizes do programa.

Não foram encontrados, dentro da psicologia social, outros estudos dedicados ao Minha Casa Minha Vida que se proponham a problematizar o tema da participação popular. Por isso, consideramos fundamental avançar em discussões a partir dessa perspectiva, tendo como objeto não só o $P M C M V$, mas também outras ações e programas de habitação voltados para o atendimento da população de baixa renda.

\section{Sobre o Minha Casa Minha Vida e a Participação Popular}

Em março de 2009, o Programa Minha Casa Minha Vida foi lançado pelo governo federal como forma de reagir à crise econômica internacional de 2008, com atuação focada no incentivo à construção e aquisição de unidades habitacionais (Maricato, 2011). O PMCMV nasceu com metas ambiciosas: em sua primeira fase, período compreendido entre 2009 e meados de 2011, tinha o objetivo de construir um milhão de moradias; em sua segunda fase, entre a segunda metade de 2011 e 2014, a meta foi dobrada (Rolnik e cols., 2015). Em 2016, após sucessivos adiamentos, foi lançada a terceira fase do programa, com meta inicial de três milhões de unidades habitacionais a serem entregues até o final de 2018, tendo sido reduzida, porém, para dois milhões em lançamento oficial (Amora $\&$ Haubert, 2016). Contudo, foi, mais uma vez, reduzida, em 2017, para $610 \mathrm{mil}$ unidades, sendo mais afetada pelo corte a faixa destinada ao atendimento das famílias mais vulneráveis - Faixa I - (Simão, 2017).

O PMCMV foi elaborado para atender três diferentes faixas de renda, com mecânicas específicas e subvenções econômicas distintas em cada uma delas (Rolnik e cols., 2015). Em 2016, os valores 
de renda familiar foram atualizados, sendo criada uma faixa intermediária, chamada de 1,5. A Faixa I passa a atender famílias com renda máxima de $\mathrm{R} \$ 1.800,00$, oferecendo subsídios de até $90 \%$ do imóvel; a recémcriada Faixa 1,5 é direcionada a famílias com renda de até $\mathrm{R} \$ 2.350,00$ e subsidiadas em até $\mathrm{R} \$ 45.000,00$.

$\mathrm{Na}$ Faixa I, é atribuição do governo municipal indicar as famílias que irão residir no empreendimento. Para participar, elas devem efetuar inscrição na prefeitura e aguardar um sorteio que definirá quais são os selecionados para cada empreendimento. A construtora responsável pela execução do projeto é remunerada diretamente com recursos do Fundo de Arrendamento Residencial (FAR), que recebe aportes do Orçamento Geral da União (OGU). Dessa forma, a empresa não fica sujeita ao risco de inadimplência dos beneficiários e não exerce qualquer atribuição relacionada à comercialização dos imóveis. As famílias inseridas no programa federal devem efetuar pagamentos mensais, calculados a partir de sua renda bruta mensal, ao longo de dez anos. Esse valor corresponde a uma parcela muito pequena do custo individual das unidades, sendo quase integralmente subsidiado com recursos do OGU. Há ainda a modalidade "Entidades", por meio da qual organizações representativas de movimentos sociais de moradia se responsabilizam pela construção dos empreendimentos e indicação dos futuros moradores. Nessa modalidade, os recursos advêm do Fundo de Desenvolvimento Social - FDS - (Rolnik e cols., 2015).

As demais faixas do PMCMV possuem condições distintas e fazem parte do chamado "mercado popular". Nesses casos, a construtora atua como incorporadora da operação e se responsabiliza pela comercialização das unidades habitacionais. Os contratos de compra e venda são celebrados diretamente com a construtora, e os compradores recebem financiamento concedido por instituição financeira federal, com subsídios econômicos que o tornam bem mais atrativo do que outros financiamentos de mercado. Apesar disso, esses incentivos são bem inferiores ao da Faixa I, cujo valor pago pelo beneficiário é praticamente simbólico. O Minha Casa Minha Vida abarca, portanto, um conjunto variado de ações com lógicas e objetivos distintos (Rolnik e cols., 2015). Todas as considerações apresentadas neste estudo remetem à primeira faixa do programa, direcionado às famílias mais vulneráveis, que conta com recursos provenientes do FAR.

Feita essa breve caracterização do $P M C M V$, faz-se pertinente, para melhor definir o propósito do artigo, apresentar sucintamente um episódio ocorrido há alguns anos, ocasião em que tivemos a oportunidade de conversar com uma futura 
moradora de um dos empreendimentos do programa. Fomos recebidos em sua antiga casa, na periferia de um município da região metropolitana de São Paulo. Chegava-se ao local com alguma dificuldade, sendo necessário descer e subir vielas íngremes com degraus improvisados. A casa era muito simples, mas zelosamente arrumada. A nossa breve conversa ocorreu no dia anterior ao evento no qual a mulher receberia as chaves do novo apartamento ela estava satisfeita. O que mais marcou, contudo, foi a emoção com que falava da casa que habitava; o trabalho e o empenho que permitiram que ela, vagarosamente, fosse ampliando e melhorando aquele espaço. Apesar das precárias condições em que vivia, pois a área em que estava era frequentemente atingida por inundações, seus olhos se enchiam de lágrimas quando falava em deixar o lugar que foi sua morada por anos.

Esse tipo de vínculo dificilmente será alcançado em sua nova residência, pois remete a uma participação real e efetiva (que, na dinâmica do $P M C M V$, parece ser sempre impedida) na construção do espaço transformado em lar. Consideramos que tal vínculo se relaciona com as múltiplas raízes de que o ser humano necessita, como destaca Simone Weil (1996, p. 411). Segundo a autora, existem necessidades não conectadas com a vida física, mas sim com as necessidades da alma. Quando não satisfeitas, fazem o ser humano, pouco a pouco, cair em um estado análogo à morte. Ainda segundo a autora, o enraizamento seria provavelmente a necessidade mais importante: "O ser humano tem uma raiz por sua participação real, ativa e natural na existência de uma coletividade que conserva vivos certos tesouros do passado e certos pressentimentos para o futuro". O enraizamento é aqui entendido, portanto, como um elemento fundamental para a vida humana e encontra-se intimamente relacionado com a possibilidade participação.

Os anseios que percebemos não atendidos pelo PMCMV, assim como os apontamentos de Simone Weil (1996) sobre enraizamento e de Hanna Arendt (2014) sobre ação - para quem toda ação está dividida em duas partes: o começo ou a iniciativa, que parte sempre de uma só pessoa; e a realização, à qual muitos se associam para conduzir, acabar, finalizar serviram de base à construção do que se denomina participação popular, neste trabalho. Em síntese, participação popular remete a uma iniciativa que, podendo partir de qualquer morador, só ganhará efeito quando encontrar a adesão coletiva e for compartilhada, permitindo a organização de um poder e a transformação daqueles que possuem papel secundário em agentes 
capazes de interferir em todas as fases da construção habitacional, uma ocasião especial de construção da própria história e superação da desigualdade - entendemos a igualdade/desigualdade como uma categoria política, relaciona-se, como pontua Gonçalves Filho (2005), com a livre manifestação do discurso e ação, práticas, geralmente, roubadas dos cidadãos pobres.

Julgamos, assim, que a o enfrentamento da desigualdade política relativa à questão habitacional não envolve apenas o atendimento concreto de uma necessidade, mas relaciona-se com ações que afirmem $o$ poder de efetiva participação. Buscamos, portanto, não apenas apontar as deficitárias possibilidades de participação popular no programa, mas também destacar a importância da participação dos moradores nos processos decisórios, aqueles que deveriam ser elemento central do processo e não apenas um componente menos importante e passivo.

\section{As Diretrizes do Programa: Trabalho Social e Obstáculos à Participação Popular}

A Portaria 93 do Ministério das Cidades, datada de 25 de fevereiro de 2010, tem por finalidade estabelecer as normas gerais do PMCMV. Deste documento, interessa destacar algumas das diretrizes apresentadas no anexo I:

a) fomento à oferta de unidades habitacionais por meio da construção de novas moradias e da requalificação de imóveis já existentes em áreas consolidadas; b) promoção da melhoria da qualidade de vida das famílias beneficiadas; [...] d) criação de novos postos de trabalho diretos e indiretos, especialmente por meio da cadeia produtiva da construção civil; [...] h) execução de trabalho técnico social, em empreendimento com regime de condomínio, entendido como um conjunto de ações voltadas para o exercício da participação cidadã, visando promover a melhoria de qualidade de vida das famílias beneficiadas e a sustentabilidade dos empreendimentos (Brasil, 2010, p. 2).

De acordo com o exposto no item "a" e "d" do artigo acima, desde o nascimento do PMCMV, nota-se a preocupação com o estímulo à construção civil e com a geração de novos postos de trabalho na área. Essa vocação é destacada por Maricato (2013) e de fato atinge resultados expressivos, como já citado.

$\mathrm{Na}$ mesma Portaria também são apresentados os participantes do Programa e suas atribuições, a saber: 
1. O Ministério das Cidades. Entre outras ações, deve estabelecer as regras e condições para implantação dos empreendimentos. Além disso, deve definir os critérios de elegibilidade e seleção dos beneficiários, assim como acompanhar e avaliar o desempenho do Programa.

2. A Caixa Econômica Federal (CEF). Agente gestora do Fundo de Arrendamento Residencial (FAR), a CEF tem a responsabilidade de expedir os atos normativos necessários para operacionalização do Minha Casa Minha Vida; contratar os executores de obras e dos serviços, aprovados segundo aspectos técnicos, jurídicos e econômicofinanceiros; contratar os executores do trabalho técnico social e acompanhar seu desenvolvimento.

3. O Distrito Federal, os estados e os municípios, os órgãos da administração direta ou indireta participantes do $P M C M V$. Algumas de suas atribuições incluem: identificação de regiões e zonas para intervenção prioritária na implantação dos projetos; indicação dos futuros moradores de acordo com os critérios estabelecidos pelo Ministério das Cidades.

4. Empresas do setor da construção civil interessadas em participar do PMCMV. Devem apresentar à Caixa Econômica Federal projetos de produção e serviços, projetos de empreendimentos para alienação dos imóveis e executar os projetos aprovados.

5. Público Alvo. Incluem cidadãos para os quais não é apresentada nenhuma atribuição, mas critérios obrigatórios que justifiquem sua inserção no programa habitacional, tais como: a limitação da renda bruta familiar mensal, condição de que o proponente não seja proprietário e não seja promitente comprador de imóvel residencial, que não seja detentor de financiamento habitacional e que não tenha recebido benefícios de natureza habitacional de recursos do OGU.

O papel reservado ao público alvo na referida Portaria, publicada na fase inicial do PMCMV, merece ressalva. Ao longo de todo o documento, o público alvo é prevalentemente designado como "beneficiário", palavra de caráter passivo que indica quem recebe ou usufrui de alguma vantagem. Tal escolha parece ser um indicativo da dinâmica que irá reger a implementação do programa.

A menção à participação do beneficiário no $P M C M V$ se resume a um item do tópico concernente ao trabalho social, quando trata do estímulo à participação cidadã, a ser efetivada por meio de: "trabalho informativo e educativo, que favoreça a organização da população, a educação sanitária e ambiental e a gestão comunitária, visando promover a melhoria 
da qualidade de vida das famílias beneficiadas" (Brasil, 2010, p. 7). Contudo, não é definido no documento o que se entende por "participação cidadã". Ela, portanto, aparece nas diretrizes do programa habitacional de forma vaga, como resultado e não como princípio, um objeto do trabalho social, este designado como um trabalho técnico.

A oposição entre operação técnica e ação leiga (oposição entre técnicos e leigos) é bem conhecida nas instituições públicas e privadas. Entendemos que o "trabalho técnico social" deve ser compreendido como uma operação que favoreça a ação, e não que seja sempre precedente a ela, acabando por substituí-la, isso exige consciente esclarecimento dos profissionais envolvidos nos processos do PMCMV. O trabalho social, para se tornar um trabalho político, precisa supor a posição sempre maior e insubstituível da participação que se pretende estimular. Contudo, as possibilidades de expressão da "participação cidadã", pretendida pela Portaria 93, mostram-se já muito limitadas, o que será perceptível também depois, na prática, uma vez que não são previstos e não serão organizados espaços de real e efetiva participação dos moradores.

Ao analisar as portarias subsequentes do $P M C M V$, nota-se que não há alteração significativa desse cenário. Algumas modificações, entretanto, devem ser destacadas e influem na dinâmica do programa, sobre seus atores e suas atribuições:

1. A Portaria 325, datada de julho de 2011 e que compreende a segunda fase do PMCMV, suprime o "público alvo" do papel de "participante". A exclusão é reveladora, reforçando o que temos afirmado relativamente à atuação popular, pois define já nas diretrizes do programa habitacional que não cabe ao "público alvo" participar de fato dos processos decisórios. Os demais atores permanecem e há inclusão das Instituições Financeiras Oficiais Federais entre os agentes executores. Essa mudança permite que, além da Caixa Econômica Federal, outras instituições financeiras federais operem no PMCMV. Quanto às atribuições dos participantes, há uma importante alteração: o trabalho social, cuja execução antes era responsabilidade da CEF, passa para a alçada do Distrito Federal, estados e municípios. À CEF caberia apenas o papel de analisar e acompanhar a execução dos projetos até sua finalização.

Essa última modificação é relevante, pois é fundamental o envolvimento mais próximo do poder público na condução de um trabalho social que, para se tornar minimamente eficaz, precisa estar articulado com as políticas públicas do município e com a rede local de assistência básica existente. Incumbir uma instituição 
financeira de executar tal trabalho é eximir o poder público local da articulação de ações que promovam mais solidamente a inclusão da população abrangida por cada novo empreendimento habitacional.

Nessa mesma Portaria, anuncia-se também considerável acréscimo nos recursos para execução do trabalho social. Antes limitados, em cada empreendimento, a $0,5 \%$ dos custos com terreno, edificações, urbanização e infraestrutura interna, os recursos com trabalho social passam ao limite de 1,5\% do valor de aquisição da unidade habitacional no caso de loteamento, e $2 \%$ nos empreendimentos sob a forma de condomínios.

Além disso, o trabalho social é apresentado de forma mais estruturada, organizado em quatro eixos principais: organização comunitária, educação ambiental, educação patrimonial e geração de trabalho e renda. Sua execução é dividida em duas etapas: fase de pré-obras, com duração de no mínimo 90 dias antes da conclusão das obras; fase de pós-obras, com duração de 180 dias após a última assinatura de contrato com morador do empreendimento, podendo ser renovado por mais 180 dias.

2. Na Portaria 465, datada de outubro de 2011, há alteração de redação no item que define o percentual de recurso destinado ao trabalho social: os percentuais tomados como teto na Portaria anterior (1,5\% loteamentos e $2 \%$ condomínios) tornam-se parâmetros obrigatórios para os empreendimentos contratados a partir de 08 de julho de 2011. Há, ainda, inclusão de subitem concernente aos empreendimentos contratados antes de julho: permite-se que seja opcionalmente utilizado o recurso complementar, proveniente do FAR, para que sejam atingidos os novos parâmetros para o trabalho social. É importante destacar que não foram criadas quaisquer ferramentas que possibilitassem participação dos futuros moradores nos processos decisórios do programa. O trabalho social, incumbido de promover a participação cidadã dos futuros moradores, apenas mereceu significativo acréscimo de recursos.

3. Novos avanços para o trabalho social seriam conquistados apenas com a publicação da Portaria 21 (ainda vigente), datada de janeiro de 2014. Com ela são definidos três diferentes instrumentos de planejamento: Projeto de Trabalho Social Preliminar (PTS-P), Projeto de Trabalho Social (PTS) e o Plano de Desenvolvimento Socioterritorial (PDST). São estabelecidos prazos e objetivos específicos para a realização de cada instrumento. O PDST é o mais estruturado, pois contempla ações organizadas em diferentes eixos, estando entre eles o “apoio à participação 
comunitária" (Brasil, 2014, p. 35). Contudo, como na Portaria 93, a eventual participação dos moradores continua sendo apresentada apenas como um dos itens do trabalho social e não como um elemento norteador do PMCMV.

De todo modo, a Portaria 21 estabelece para o trabalho social um escopo de atividades muito mais robusto do que aquele originalmente formulado para o Minha Casa Minha Vida. A criação de diferentes instrumentos (PTS-P, PTS e PDST) estipula marcos temporais mais precisos e extensos para o planejamento e a execução do trabalho social. Segundo a Portaria, as ações sociais devem começar quando o empreendimento estiver em fase inicial de construção; precedentemente, o trabalho social começava somente três meses antes da data estimada para a finalização da construção. A partir da publicação da Portaria, o primeiro instrumento do trabalho social (PTS-P) deve ser concluído até que a construção do empreendimento atinja $65 \%$ de execução. Tal parâmetro permite que o trabalho social seja iniciado ainda nas fases inaugurais das obras.

As modificações incorporadas possibilitaram a resolução de um problema existente desde o início do PMCMV: as ações do trabalho social eram, muitas vezes, formuladas sem que ainda estivessem definidos quais seriam os moradores do empreendimento. Assim, as atividades eram planejadas sem qualquer diagnóstico preciso da população à qual se destinavam e, portanto, a partir de informações muito genéricas a respeito do seu público alvo. $\mathrm{O}$ estudo de Cardoso, Mello e Jaenisch (2015), sobre a implementação do programa federal na região metropolitana do Rio de Janeiro, denunciou um quadro em que as ações do trabalho social eram não só elaboradas, mas também colocadas em prática sem conhecimento das características do público alvo.

Diante dessa conjuntura, as diretrizes estabelecidas pela Portaria 21 poderiam amenizar traços fortemente burocráticos e consequentemente impessoais do PMCMV. A escolha das famílias moradoras dos conjuntos habitacionais do programa, determinada já nas fases iniciais do empreendimento, possibilitaria um trabalho mais efetivo de colaboração entre esses grupos e a equipe de trabalho social, antes mesmo da mudança para a nova moradia. Importa aqui salientar que a Portaria - elaborada com a consulta e participação de vários agentes envolvidos na operacionalização do $P M C M V$ - buscou promover a participação dos moradores como um de seus pontos primordiais. Apesar dos avanços, o documento (até mesmo por ter como finalidade dar novas diretrizes ao planejamento e execução do trabalho social e não redefinir a dinâmica do 
$P M C M V$ ) não abarcou dispositivos que assegurassem o cumprimento das metas previamente estabelecidas. Não houve, por exemplo, respaldo para a paralisação das obras quando atingissem $65 \%$ de execução e ainda não tivessem sido indicados os moradores (ação prevista no PTS-P e que deveria estar concluída no marco apontado). Tal mecanismo, forçando maior celeridade na definição do grupo de moradores, promoveria maior possibilidade de organização e participação popular. A

Portaria não foi munida de instrumentos que garantissem uma efetiva participação dos moradores. O ímpeto para a conclusão das obras continuou (e continua) tendo importância maior, desligado da atenção e dos cuidados que deveriam ser direcionados aos que transformarão as construções em lar. A falta de dispositivos mais incisivos, que assegurassem o cumprimento das diretrizes previstas no $P M C M V$, tem prejudicado todo o planejamento $\mathrm{e}$ execução das ações no trabalho social e, afinal, da própria sustentabilidade do empreendimento.

As consequências dessa fragilidade nas normas institucionais são várias. Tomemos como uma das mais evidentes: a dinâmica que domina o processo de indicação das famílias para o Minha Casa Minha Vida. Rufino (2015) considera que a falta de transparência na construção do cadastro e nos processos de sorteio e a demora na entrega da lista de futuros moradores para a CEF se configuram como problemas que prejudicam uma atuação mais segura e orientada dos técnicos sociais, além de facilitarem a influência ou mesmo controle do tráfico e de milícias em inúmeros empreendimentos. Cardoso, Mello e Jaenisch (2015) também destacam o impacto do encaminhamento tardio das listas, fato recorrente que impossibilita suportes certeiros aos futuros moradores, melhor ajustados a suas necessidades e anseios. Analisar o perfil dos moradores, antes, durante e depois de escolhê-los, tornaria muito mais eficiente o modo de colaborar com eles e prepará-los para a mudança residencial, tornaria mais pertinentes as reuniões de esclarecimento (que se tornariam esclarecimentos mútuos) e organizaria de modo muito mais significativo os sorteios das unidades.

O Minha Casa Minha Vida não evitou um desvio no processo, como poderia ser almejado por se tratar de um programa de habitação de interesse social, pelo contrário, reforça uma lógica em que a construção das moradias populares se tornou mais relevante do que as pessoas para as quais tais imóveis são construídos. A preocupação com a edificação dos empreendimentos ofusca outras demandas, torna marginal o tratamento de questões que 
se ligam às finalidades primordiais do $P M C M V$ e que mais deveriam sobressair: "a promoção da melhoria da qualidade de vida das famílias beneficiadas" (Brasil, 2010, p. 2). Assim, o morador é, muitas vezes, entendido pelos agentes do PMCMV como um entre outros diversos itens operacionais.

Dessa forma, como lemos em Honneth (2008), os agentes operam dentro do processo de reificação, o qual pressupõe deixar de perceber nas outras pessoas as características que as tornam propriamente humanas: tratar alguém como "coisa" significa justamente tomar "alguém" como "algo", despido de quaisquer características ou habilidades que superem a existência meramente material. $\mathrm{O}$ morador é percebido e tratado como alavanca ou obstáculo, favorável ou desfavorável, do mesmo modo que outros diversos objetos do programa; os beneficiários são meios, entre outros, para que o processo das obras chegue ao fim. Nas sucessivas etapas do empreendimento, as relações com os moradores tornam-se então instrumentais, sempre vazias, porque abstratas e impessoais: relações instrumentais, relações cada vez mais desumanizadas.

A burocratização e a reificação possuem dinâmicas que se interrelacionam. Quando tomada como um fenômeno capitalista, pode-se considerar a reificação como fator de renovação moderna da burocracia. Segundo Weber
(1966), a burocracia é feita de atores e de mecanismos institucionais aplicados ao exercício da dominação por meio de um quadro administrativo anônimo: busca-se atingir o mais alto grau de eficiência dentro de uma perspectiva puramente técnica, carregada de percepções e operações muito gerais, válidas para todo agrupamento de pessoas e conduzidas como a forma conhecida e mais racional de organizar ações. Lukács (2003, p. 219), considera que: "A burocracia implica uma adaptação do modo de vida do trabalho e paralelamente também da consciência aos pressupostos socioeconômicos gerais da economia capitalista". O autor afirma que a atividade burocrática opera objetivamente (de maneira formal e racionalista), promovendo o desprezo da essência qualitativa de tudo com que se relaciona. A desumanização das relações é, portanto, condição fundamental para o funcionamento de um modelo burocrático, dinâmica que permite sempre ligar os dois fenômenos: burocratização e reificação.

A análise da mecânica de implementação do Minha Casa Minha Vida ganha muito quando voltamos nossa atenção para o modo de funcionamento da administração burocrática. Merton (1966, p. 98) destaca como principal trunfo da burocracia a aparente eficiência técnica, a precisão, a rapidez, o controle, a continuidade, a discrição e a produtividade. 
Para tanto, considera que a comunicação e o comportamento, as conversas e as ações devem "eliminar por completo as relações do tipo pessoal e as considerações emocionais". Merton fala na eliminação da hostilidade, da ansiedade, dos vínculos afetivos, e a lista de eliminações pode crescer: a simpatia, a confiança, o confronto, a conversa, a discussão.

Importa sintetizar dois pontos fundamentais acerca da administração burocrática:

1. A reificação é inerente ao seu funcionamento - assim como, segundo Lukács (2003), todas as condições econômicas e sociais do nascimento do capitalismo moderno demandam que as relações originais, mais transparentes, sejam substituídas por relações racionalmente reificadas;

2. Opera sempre em uma perspectiva formal, técnica e do tipo mais racional possível, primando por uma pretensa eficiência técnica.

Esses dois elementos são indispensáveis para avançarmos no entendimento do funcionamento $P M C M V$. O programa opera dentro de um modelo com traços fortemente burocráticos, a produção de moradias em massa se torna seu objetivo primordial. Para alcançar essa almejada eficiência, as relações entre os agentes responsáveis pela condução do
Minha Casa Minha Vida e os moradores se consolidam como predominantemente reificadas. Desligadas de qualquer vínculo pessoal, considerações emocionais, tornando-se, assim, relações desumanizadas.

As relações reificadas dominam a dinâmica de implementação do programa e justificam o tratamento dado aos moradores já nas diretrizes do $P M C M V$, uma vez que eles representam apenas um entre diversos itens a serem verificados para que a produção em série de moradias seja possível. Os moradores não são considerados como parte apta a participar do processo, já que, muitas vezes, sequer são reconhecidas as características que os fazem humanos.

A efetiva participação popular no Minha Casa Minha Vida requer, portanto, uma ruptura com a burocracia e consequentemente com a reificação das relações que prevalecem nos processos do programa. Como já pontuamos, o trabalho social é o instrumento (limitado pela lógica que domina do $P M C M V$ ) responsável por promover a participação dos moradores. Contudo, essa participação está, sobretudo, restrita às ações do próprio trabalho social. Defendemos que ela ganhe dimensão mais abrangente e consideramos tal condição como elemento fundamental para real apropriação da nova moradia. $\mathrm{O}$ que 
queremos afirmar é que a participação necessita assumir grandeza maior, deve tornar-se uma experiência básica e uma experiência chave, precisa acontecer não apenas na relação dos moradores com os técnicos sociais, mas também nas relações dos moradores com os demais agentes do programa. Os moradores precisariam sentir e verificar que participam do processo, que alteram de forma mais contundente a nova realidade em que foram inseridos.

Para que a nossa concepção de participação popular não fique demasiadamente abstrata, é importante elencar algumas das ações por meio das quais ela poderia ser efetivada (é possível conhecer experiências do PMCMV conduzidas por movimentos sociais que envolvem, em maior ou menor grau, algumas das ações participativas sugeridas aqui): oportunidade de escolha da região onde os moradores prioritariamente gostariam de residir; escolha do apartamento (definição que geralmente é feita de forma aleatória); participação na construção do projeto do empreendimento (que poderia envolver diversas ações, em diferentes etapas, relacionadas tanto à configuração da planta da residência tamanho e quantidade de cômodos - como também à escolha do piso, cor da pintura, nome do empreendimento); possibilitar que a definição do grupo de moradores que irá residir em um mesmo empreendimento seja participativa, de forma a permitir que sejam respeitados laços familiares e de vizinhança, local original de domicílio, local de trabalho, entre outros elementos que valorizem a dimensão qualitativa do processo.

\section{Modelo de Gestão Pública e Participação Popular}

Seria injusto criticar a dinâmica de implementação do PMCMV de maneira isolada. É necessário, portanto, considerar alguns aspectos dos modelos gerais de gestão pública existentes no Brasil. Segundo Paula (2005a), podemos identificar dois projetos políticos em desenvolvimento e disputa. Ambos modelos são herdeiros do processo de redemocratização do país, período em que se buscou um modelo de gestão pública mais aberto às necessidades dos cidadãos, eficiente e voltado para o interesse público. Um deles, de inspiração gerencial, foi efetivamente implementado no governo do ex-presidente Fernando Henrique Cardoso. Segundo Bresser-Pereira (2003) responsável pela reforma da gestão pública de 1995-98 - o modelo gerencial é uma nova forma de organizar o estado, opondose à administração pública burocrática, a qual pretende substituir. O outro - de inspiração propriamente social, como o são os projetos cujas raízes remontam às 
mobilizações populares contra a ditadura encontra-se em estágio incipiente, manifesta-se nas experiências alternativas de gestão pública, como os conselhos gestores e orçamento participativo.

A origem do modelo gerencial está ligada ao debate sobre a crise de governabilidade e credibilidade do Estado na América Latina nas décadas de 1980 e 1990 e relaciona-se com um ideário que floresceu durante os governos de Margareth Thatcher e Ronald Reagan. Tanto no Reino Unido quanto nos Estados Unidos, o movimento no setor público é baseado na cultura do empreendedorismo, reflexo do capitalismo flexível que se consolida por meio da criação de um código de valores e condutas que buscam garantir controle, eficiência e competitividade máximos.

Segundo crítica de Paula (2005b, p. 52), a administração pública gerencial pode até buscar ser menos burocrática, sendo que algumas características do tipo ideal weberiano foram de fato superadas. No entanto, a dominação burocrática persiste, impactando nos possíveis processos democráticos participativos, uma vez que "seus idealizadores têm uma noção muito particular do que seja democracia e, em geral, dedicam mais atenção à representação e às instituições democráticas do que à construção de uma cultura política participativa".
Já a administração pública societal, assim chamada pela autora, segue os marcos e ápices das grandes mobilizações políticas dos brasileiros que atingiram seu pico no início da década de 1960, sofrendo depois repressões ou desfalques e alcançando recuperação em meados e finais da década de 1970. Paula (2005a) destaca que, após o golpe de 1964, as mobilizações retornaram na década de 1970 , período no qual a Igreja Católica catalisou a discussão de problemas coletivos nas Comunidades Eclesiais de Base (CEBs), a partir de ideais infundidos pela teologia da libertação e educação popular. O cerne do movimento que inspira o modelo societal é a participação popular na gestão pública.

De acordo ainda com a autora, a vertente gerencial de gestão pública enfatiza a dimensão econômico-financeira e institucional-administrativa; já a vertente social prioriza a dimensão sociopolítica. A vertente gerencial é introvertida, ocupada com soluções chamadas organizacionais para as instituições todas tomadas como empresas; ou, quando extrovertida, quer calibrar ou ajustar mecanismos econômicofinanceiros, assumindo como máquina ou grande aparelho os processos societários a serem administrados. A vertente social privilegia as consultas populares. A vitória de Luiz Inácio Lula da Silva nas eleições presidenciais de 2002 gerou a expectativa 
de que a abordagem social se tornasse marca do governo federal. Contudo, o que se observou foi a manutenção de práticas da vertente gerencial, inclusive no campo das políticas sociais (Paula, 2005a).

No Programa Minha Casa Minha Vida, podemos identificar a influência do modelo de gestão gerencial, embora o programa tenha se pretendido eminentemente social. Observa-se essa ascendência, sobretudo, quanto a um dos traços da gestão gerencial: "participativo no nível do discurso, mas centralizador no que se refere ao processo decisório, à organização das instituições políticas e à construção de canais de participação popular" (Paula, 2005a, p. 41). Corrobora Souza (2015) que, no modelo gerencial de Estado, as políticas públicas tornam-se meramente resultado de consensos artificiais moldados pelo agir instrumental: acabam ignorando ou neutralizando discursos antagonistas, despolitizando espaços de articulação das diferenças, desperdiçando as oportunidades de troca (troca de pontos de vista, troca de palavras, troca de iniciativas). A centralização administrativa é dominante na estrutura mesma do Estado brasileiro, impedindo a participação popular efetiva. Essas características relacionam-se à fragilidade da sociedade civil, historicamente servil; e à formação da elite brasileira, conservadora ou francamente reacionária, defensiva, mantida nos limites de uma ideologia autoritária e de uma democracia ainda fortemente liberal.

O PMCMV não conta com suficiente abertura democrática e, de acordo com a posição de Lopes e Shimbo (2015), inibe ações que não tenham foco senão na produção das unidades habitacionais, produção está julgada por índices quantitativos (traço também característico a almejada eficiência - da administração burocrática e do modelo de gestão gerencial); o foco entre viseiras não permite abarcar problemas qualitativos, tidos como laterais. Os mecanismos de funcionamento do programa habitacional estão, ao fim, regulados apenas pelos parâmetros de um negócio imobiliário bem-sucedido, aferido segundo seus custos e benefícios numéricos. Os autores afirmam com severidade:

Desse modo, a provisão habitacional pauta-se antes pela 'lógica dos negócios', do que por uma lógica de planejamento urbano e de atendimento às reais necessidades habitacionais. $\mathrm{A}$ forma pela qual a máquina opera não proíbe a participação de outros agentes (como entidades e prefeituras), mas inibe iniciativas pautadas por outros pressupostos (exemplos: direito à cidade, necessidades habitacionais etc.). (Lopes \& Shimbo, 2015, p. 243) 
O modelo de gestão social se relaciona diretamente com o conceito de cidadania. Cidadania inclui e é mais que ação deliberativa: são muitos atos além das deliberações, os quais as precedem, acompanham e sucedem. São atos de falar e ouvir. São atos de opinar e pensar com os outros. É o ato de conversar longamente. São atos de colaboração. São conversas sobre assuntos que podem estar ligados à construção da casa, mas também assuntos que ajudem a perscrutar o sentido psicológico e político da posse de uma casa. E são conversas que se tornam capazes até de assuntos desligados da casa, mas pertinentes entre cidadãos que dividem uma mesma cidade, um mesmo país, um mesmo mundo.

Assim, o exercício de cidadania supõe ações por meio das quais se pode alcançar a participação que permite ao sujeito decidir a respeito do seu destino social e pessoal, sua autodeterminação em conjugação com a determinação de destinos coletivos (Tenório, 1998). É necessário, portanto, que o direito à participação seja acompanhado pelo favorecimento dos elementos sócio-históricos, psicossociais e psicopolíticos que se relacionam com as múltiplas vivências dos sujeitos em casa e na cidade, suas diferentes formas de mobilização humana. Conforme Silva (2012, p. 235), os sujeitos precisam ser admitidos como agentes aptos "a participar efetivamente e afetivamente do processo de governança."

\section{Considerações Finais}

Procuramos, ao longo desse trabalho, identificar e discutir os processos de participação popular no Minha Casa Minha Vida. Inicialmente, partindo da análise dos documentos que regulamentam o programa, fonte fundamental do estudo, apontamos o papel de cada agente, destacamos as menções à participação dos moradores e os instrumentos que permitiriam que ela se efetivasse. Consideramos, de pronto, que as diretrizes do PMCMV inibem processos de participação popular - concluindo, portanto, que a prática pouco participativa que observamos em campo não decorre de eventual distorção das normas do programa - e que o trabalho social é o único item responsável por promover ações que a possibilitem, embora sejam de alcance demasiadamente limitado. Buscamos, então, relacionar os obstáculos à efetiva participação popular com os processos burocráticos e as relações reificadas que dominam a mecânica de implementação do programa, heranças renitentes de um modelo de administração gerencial. 
Julgamos não ter explorado totalmente complexa temática, contudo, o objetivo primordial do trabalho foi apontar as possibilidades (e impossibilidades) de participação popular no $P M C M V$, destacar sua importância e suscitar seu debate. Entendemos a participação como elemento fundamental de análise do programa, item essencial para assegurar a sustentabilidade dos empreendimentos e consequentemente a permanência das famílias no novo espaço. Consideramos que a moradia é um lugar de enraizamento, da criação de raízes cuja existência e manutenção necessitam do exercício da participação. Defendemos, portanto, que a participação popular se torne experiência basilar no Minha Casa Minha Vida.

Os avanços promovidos pelo PMCMV precisam ser reconhecidos. $\mathrm{O}$ programa foi um marco na política habitacional brasileira, com a inclusão de subsídio como elemento fundamental e a produção de moradias populares em massa. Tem méritos por ter conseguido aportar recursos bilionários, como nunca havia acontecido antes, para o atendimento à população de baixa renda (Bonduki, 2014). Contudo, ele tem um longo caminho a percorrer se colocado em seu horizonte o exercício da cidadania e da igualdade política. Iniciativa imprescindível será dar voz e assegurar possibilidades de participação a quem a política pública se destina. O êxito dessa empreitada depende de transformações na mecânica de implementação do programa, de forma a permitir que se estabeleçam relações mais humanizadas e horizontais entre os diferentes agentes envolvidos no processo.

\section{Referências Bibliográficas}

Amora, Dimini, \& Haubert, Mariana. (2016, 30 de março de). Governo faz evento para anunciar redução de meta de casas populares. Folha On-line, Acessado em 10 de julho de 2016, de <http://www1.folha.uol.com.br/mercado/2016/03/1755546-governo-faz-eventopara-anunciar-reducao-de-meta-de-casas-populares.shtml $>$

Arendt, Hanna. (2014). A condição humana (12 ed.). Tradução de Roberto Raposo. Rio de Janeiro: Forense Universitária.

Bonduki, Nabil. (2014). Cem anos de construção da política pública de habitação no Brasil: o desafio de uma arquitetura para a maioria. Em Nabil Bonduki. Os Pioneiros da Habitação Social no Brasil: volume 1. (1 $1^{\mathrm{a}}$ ed., pp. 1 - 129). São Paulo: Unesp.

Brasil. (2010). Diário Oficial da União. Brasília: Ministério das Cidades. Portaria no 93, de 25 de Fevereiro de 2010. Acessado em: 2 de maio de 2016, de < http://www.cidades.gov.br/images/stories/Legislacao/Portarias_2010/Portaria_93_2010.p df> 
Brasil. (2011). Diário Oficial da União. Brasília: Ministério das Cidades. Portaria no 325, de 7 de Julho de 2011. Acessado em: 2 de maio de 2016, de < http://pesquisa.in.gov.br/imprensa/jsp/visualiza/index.jsp?jornal=1\&pagina $=57 \&$ data $=21 /$ 07/2011/index.jsp?jornal $=1 \&$ pagina $=57 \&$ data $=21 / 07 / 2011>$

Brasil. (2011). Diário Oficial da União. Brasília: Ministério das Cidades. Portaria $n^{\circ} 465$, de 21 de Julho de 2011. Acessado em: 2 de maio de 2016, de < http://pesquisa.in.gov.br/imprensa/jsp/visualiza/index.jsp?.jornal=1\&pagina $=57 \&$ data $=21 /$ 07/2011/index.jsp?data=04/10/2011\&jornal=1\&pagina=31\&totalArquivos=216>

Brasil. (2013). Diário Oficial da União. Brasília: Ministério das Cidades. Portaria $\mathrm{n}^{\mathrm{o}}$ 595, de 18 de Dezembro de 2013. Acessado em: 2 de maio de 2016, de < http://pesquisa.in.gov.br/imprensa/jsp/visualiza/index.jsp?data=20/12/2013\&jornal=1\&pa gina $=99 \&$ totalArquivos $=184>$

Brasil. (2014). Diário Oficial da União. Brasília: Ministério das Cidades. Portaria no 21, de 22 de Janeiro de 2014. Acessado em: 2 de maio de 2016, de < http://www.cidades.gov.br/images/stories/ArquivosCidades/PAC/Manuais-Gerais$\mathrm{PAC} /$ portaria21.pdf>

Bresser-Pereira, Luiz Carlos (2003). Réplica: comparação impossível. RAE Revista de Administração de Empresas, 45 (1), 50-51. Acessado em: 10 de junho de 2016, de https://dx.doi.org/10.1590/S0034-75902005000100006

Cardoso, Adauto Lúcio; Mello, Irene Queiroz e. \& Jaenisch, Samuel Tomas (2015). A implementação do Programa Minha Casa Minha Vida na Região Metropolitana do Rio de Janeiro: agentes, processos e contradições. Em Caio Santo Amore, Lúcia Zanin Shimbo, \& Maria Beatriz Cruz Rufino. (Orgs.), Minha casa... e a cidade? Avaliação do Programa Minha Casa Minha Vida em seis estados brasileiros. (1 ${ }^{\mathrm{a}}$ ed., pp. 73 - 102). Rio de Janeiro: Letra Capital.

Gonçalves Filho, José Moura. (2005). Problemas de método em Psicologia Social: algumas notas sobre a humilhação política e o pesquisador participante. Em Ana M. Bahia Bock, (Org.), Psicologia e o compromisso social ( $2^{\circ}$ Ed.). São Paulo: Editora Cortez.

Honneth, Axel (2008). Observações sobre a reificação. Civitas, 8(1), 68-79. Acessado em: 19 de janeiro de 2016, de http://revistaseletronicas.pucrs.br/ojs/index.php/civitas/article/view/4322/6868>. doi.org/10.15448/1984-7289.2008.1.4322

Lopes, João Marcos de Almeida. \& Shimbo, Lúcia Zanin. (2015). Um olhar sobre a produção do PMCMV a partir de eixos analíticos. Em Caio Santo Amore, Lúcia Zanin Shimbo, \& Maria Beatriz Cruz Rufino. (Orgs.), Minha casa... e a cidade? Avaliação do Programa Minha Casa Minha Vida em seis estados brasileiros. (1 ${ }^{\text {a }}$ ed., pp. 229 - 254). Rio de Janeiro: Letra Capital. 
Lukács, George. (2003). O fenômeno da reificação. Em George Lukács. História e Consciência de Classe: Estudos sobre a dialética marxista. (1 ${ }^{\text {a }}$ ed., pp 194-239). São Paulo: Martins Fontes.

Maricato, Ermínia. (2003). Metrópole, legislação e desigualdade. Estudos Avançados, 17(48), 151-166. Acessado em: 23 de agosto de 2013, de https://dx.doi.org/10.1590/S010340142003000200013

Maricato, Ermínia. (2011). O Impasse da Política Urbana. Em Ermínia Maricato. O Impasse da Política Urbana no Brasil (pp. 15 - 88). Petrópolis: Vozes.

Maricato, Ermínia. (2013). É a questão urbana, estúpido! Em Alexandre Peschanski, Carlos Vainer, David Harvey, Ermínia Maricato, Jorge Luiz Souto Maior, Leonardo Sakamoto, Lincoln Seco, Mauro Luis Iasi, Mike Davis, Pedro Rocha de Oliveira, Raquel Rolnik, Ruy Braga, Silvia Viana, Slavoj Zizek, Venício A. de Lima. Cidades Rebeldes: passe livre e manifestações que tomaram as ruas do Brasil. São Paulo: Boitempo.

Merton, Robert King. (1966). Estrutura Burocrática e Personalidade. Em Edmundo Campos. (Org.), Sociologia da Burocracia (2 ${ }^{\mathrm{a}}$ ed. pp. 96-110). Rio de Janeiro: Zahar Editores.

Paula, Ana Paula Paes de. (2005a). Administração pública brasileira entre o gerencialismo e a gestão social. Revista de Administração de Empresas, 45(1), 36-49. Acessado em: 15 de maio de 2016, de http://www.scielo.br/scielo.php?script=sci_arttext\&pid=S003475902005000100005

Paula, Ana Paula Paes de. (2005b). Tréplica: comparação possível. Revista de Administração de Empresas, 45(1), 51-52. Acessado em 10 de junho de 2016, de https://dx.doi.org/10.1590/S0034-75902005000100007

Rolnik, Raquel. (2014). Ferramentas para avaliação da inserção urbana dos empreendimentos do MCMV. Projeto de Pesquisa da Faculdade de Arquitetura e Urbanismo da Universidade de São Paulo, Equipe Laboratório Espaço Público e Direito à Cidade. São Paulo: Universidade de São Paulo. Acessado em: 03 de outubro de 2015, de < http://www.labcidade.fau.usp.br/arquivos/relatorio.pdf>

Rolnik, Raquel, Pereira, Alvaro Luis dos Santos, Moreira, Fernanda Accioly, Royer, Luciana de Oliveira, Iacovini, Rodrigo Faria Gonçalves, \& Nisida, Vitor Coelho. (2015). O Programa Minha Casa Minha Vida nas regiões metropolitanas de São Paulo e Campinas: aspectos socioespaciais e segregação. Cadernos Metrópole, 17(33), 127-154. Acessado em: 20 de abril de 2016, de https://dx.doi.org/10.1590/2236-9996.2015-3306

Rufino, Maria Beatriz Cruz. (2015). Um olhar sobre a produção do PMCMV a partir de eixos analíticos. Em Caio Santo Amore, Lúcia Zanin Shimbo, \& Maria Beatriz Cruz Rufino. (Orgs.), Minha casa... e a cidade? Avaliação do Programa Minha Casa Minha Vida em seis estados brasileiros. ( $1^{\text {a }}$ ed., pp. $51-72$ ). Rio de Janeiro: Letra Capital.

Silva, Alessandro Soares da. (2012). Enfoque Psicopolítico da Intervenção em Políticas Públicas. Em Alessandro S. Silva. Psicologia Política, Movimentos Sociais e Políticas Públicas. Tese de Livre Docência, Escola de Artes, Ciências e Humanidades. São Paulo: Universidade de São Paulo. 
Simão, Edna. (2017, 10 de outubro de). Restrição fiscal afeta Minha Casa e faz sumir recursos para baixa. Valor Econômico. Acessado em 10 de outubro de 2017, de $<$ http://www.valor.com.br/brasil/5031936/restricao-fiscal-afeta-minha-casa-e-faz-sumirrecursos-para-baixa-renda>

Souza, Telma R. de Paula. (2015). Políticas Públicas no Enfoque da Psicologia Política. Em Alessandro S. Silva, \& Felipe Corrêa. (Orgs.), No Interstício das Disciplinaridades: A Psicologia Política. (1 ${ }^{a}$ ed., pp. 219-237). Curitiba: Editora Prismas.

Tenório, Fernando G. (1998). Gestão social: uma perspectiva conceitual. Revista de Administração Pública, 32 (5), 7-23. Acessado em: 14 de junho de 2016, de < http://bibliotecadigital.fgv.br/ojs/index.php/rap/article/viewFile/7754/6346>

Weber, Max. (1966). Os Fundamentos da Organização Burocrática: Uma Construção do Tipo Ideal. Em Edmundo Campos. (Org.), Sociologia da Burocracia (2a ed. pp. 9-15). Rio de Janeiro: Zahar Editores.

Weil, Simone. (1996). O Desenraizamento. Em Ecléa Bosi (Org.), A condição operária e outros estudos sobre a opressão ( $2^{\mathrm{a}}$ ed., pp. 409-440). Rio de Janeiro: Paz e Terra.

\section{O autor:}

Douglas Cardoso da Silva possui graduação em psicologia pela Universidade Cruzeiro do Sul (2009), especialização em teoria psicanalítica pela Pontifícia Universidade Católica (2011) e mestrado em Psicologia Social pela Universidade de São Paulo (2017). Atua, desde o ano de 2011, junto a prefeituras e movimentos sociais de moradia na orientação de projetos sociais vinculados ao Programa Federal Minha Casa, Minha Vida. E-mail: douglas.c.silva@usp.br

Recebido em: 22/06/2018

Aceito em: 28/12/2018 